\title{
Interés general General Interest
}

\author{
Pablo Acosta Gallo \\ Universidad Rey Juan Carlos de Madrid \\ pablo.acosta@urjc.es
}

Recibido / received: 02/05/2018

Aceptado / accepted: 23/01/2019

DOI: https://doi.org/10.20318/eunomia.2019.4698

\section{Resumen}

El concepto de interés general está sólidamente implantado en nuestra Constitución y en nuestro textos legales. La cláusula "intereses generales" legitima la acción de gobierno y la existencia misma del Estado, así como sus poderes de limitación de las esferas de libertad de los ciudadanos. Sin embargo, nuestro ordenamiento jurídico no ofrece una definición de lo que son los intereses generales. En este estudio se intentan encontrar las características que permiten orientar la acción administrativa hacia la satisfacción de los intereses generales, así como identificar los elementos que construyen el concepto.

\section{Palabras clave}

Interés general, intereses generales, utilidad pública, interés social, servicio público.

\begin{abstract}
The concept of general interest is firmly implanted in our Constitution and in our legal texts. The clause "general interests" legitimizes the action of government and the very existence of the State as well as its powers to limit the spheres of freedom of citizens. However, our legal system does not offer a definition of what general interests are. In this study we try to find the characteristics that allow us to orient the administrative action towards the satisfaction of the general interests as well as to identify the elements that construct the concept.
\end{abstract}

\section{Keywords}

General interest, general interests, public utility, social interest, public service

SUMARIO. 1. La idea de servicio a los intereses generales. 2. EI concepto de interés general en nuestra Constitución. 3. La insuficiencia del criterio de la mayoría en la definición del concepto de interés general. 4. El interés general como concepto jurídico indeterminado. 5. El contenido del concepto de interés general. 6. Conclusiones. 


\section{La idea de servicio a los intereses generales}

Según dispone la Constitución Española, en su art. 103.1: "La Administración Pública sirve con objetividad los intereses generales...". Nótese que la literalidad del artículo no indica la constitución de una obligación a cargo de las Administraciones Públicas, sino la auténtica constatación de un hecho incontestable: que su razón de ser no es otra que el servicio al interés general. El texto constitucional establece de este modo que la procura del interés general opera como cláusula de justificación y legitimación de los poderes y prerrogativas de las Administraciones Públicas en su actividad organizativa y de gestión. Cuando las diferentes administraciones, en sus diferentes niveles, constituyen órganos, disponen normas o gestionan servicios públicos, no es que lo hagan con una orientación hacia el beneficio del interés general; es que lo hacen con la idea única de servir con objetividad los intereses generales. Por tanto, una primera aproximación nos permite afirmar que el concepto de interés general justifica no sólo la actividad de las Administraciones Públicas, sino la existencia misma del propio Estado.

En un contexto de adelgazamiento del Estado, al menos en cuanto al debilitamiento del llamado Estado de Bienestar y a la privatización de algunos servicios públicos que antes eran de prestación directa, ¿sigue teniendo vigencia la idea de servicio a los intereses generales? Evidentemente sí, pues la formulación del artículo 103.1 de la Constitución de 1978 convierte los intereses generales en un concepto abstracto y formal que expresa "el fin institucional mismo de la Administración, del conjunto de Administraciones públicas, en cuanto poder público", según ha afirmado el profesor Parejo Alfonso (1998: 605).

Las potestades exorbitantes del Derecho común que el ordenamiento jurídico otorga a las Administraciones Públicas se justifican y explican por tanto en el hecho de que la Administración, como persona jurídica, está constitucionalmente vinculada al servicio de los intereses generales. Queda claro, por tanto, para qué sirve el interés general, pero más difícil es ofrecer una delimitación del concepto, puesto que la Constitución no parece dar una pista clara de lo que son los intereses generales, al menos en abstracto.

En este contexto, resulta esencial dilucidar si el interés general es un concepto político o jurídico, cuestión que ha ocupado durante largo tiempo a la doctrina. La pregunta no es baladí, pues si se decide que es un concepto político, su contenido dependerá del programa político del partido gobernante, o incluso de la interpretación de las circunstancias del caso concreto que haga el funcionario a cargo cuando tenga que decidir qué beneficia más al interés general. Si, por el contrario, se considera que el interés general es un concepto jurídico, su aplicación deberá fundamentarse en una interpretación de las normas jurídicas aplicables al caso concreto. Si el interés general es un concepto jurídico, sus notas esenciales quedarán a salvo de una eventual libre interpretación de los gestores de lo público.

\section{El concepto de interés general en nuestra Constitución}

La fórmula "interés general" o "intereses generales" aparece con frecuencia en nuestro ordenamiento jurídico, de forma literal o bajo denominaciones similares, como "utilidad pública" o "interés social" en la legislación de expropiación forzosa; también "interés económico general" en la legislación comunitaria como cláusula que obliga a la prestación de determinados servicios públicos por parte de los Estados. El término se usa también en diversas materias: economía, calificaciones de obra pública, 
puertos, fundaciones, investigación y desarrollo, ayudas públicas, incentivos fiscales y otros sectores.

La Constitución Española de 1978 utiliza la expresión "interés general” en una docena de ocasiones ${ }^{1}$.

El mismo término, en plural, es utilizado en una única ocasión, que sin embargo es la más relevante a efectos de la acción de gobierno y administración de los recursos del Estado, en el ya citado artículo 103.1 de la Constitución Española².

La utilización en el texto constitucional del término "interés general" en sus distintas formas opera como condición necesaria en la regulación de distintas materias. El hecho de que en la Constitución no se defina, con carácter autónomo, en qué consiste el interés general, tiene sin duda un significado, pues el legislador constituyente renunció a encorsetar el concepto mediante una formulación cerrada, prefiriendo dejar abierto a interpretación en cada caso qué ha de entenderse por interés general.

La consulta de los estudios doctrinales en torno a los servicios de titularidad pública tampoco se ha detenido especialmente en la cuestión de la naturaleza jurídica del interés general. El profesor Muñoz Machado, quien ha analizado de forma exhaustiva la figura del servicio público y sus variantes -servicios de interés general, servicios de interés económico general, servicios sociales de interés general, servicios no económicos de interés general, servicio universal, misiones de servicio público-, afirma en todos estos casos que existe una reserva a favor del Estado de la prestación de estos servicios porque esta reserva es necesaria para satisfacer los intereses generales (2011: 562 y ss.). Parece desprenderse de esta afirmación que los intereses generales constituyen un concepto de carácter táctico o finalista en cada área de intervención de las distintas administraciones, que deberán operar en cada

${ }^{1}$ En concreto, en los siguientes artículos del texto constitucional:

"Art. 30.3. Podrá establecerse un servicio civil para el cumplimiento de fines de interés general."

"Art. 34.1. Se reconoce el derecho de fundación para fines de interés general, con arreglo a la ley."

"Art. 44.2. Los poderes públicos promoverán la ciencia y la investigación científica y técnica en beneficio del interés general."

"Art. 47. Todos los españoles tienen derecho a disfrutar de una vivienda digna y adecuada. Los poderes públicos promoverán las condiciones necesarias y establecerán las normas pertinentes para hacer efectivo este derecho, regulando la utilización del suelo de acuerdo con el interés general para impedir la especulación."

"Art. 128.1. Toda la riqueza del país en sus distintas formas y sea cual fuere su titularidad está subordinada al interés general."

"Art. 128.2. Se reconoce la iniciativa pública en la actividad económica. Mediante ley se podrá reservar al sector público recursos o servicios esenciales, especialmente en caso de monopolio, y asimismo acordar la intervención de empresas cuando así lo exigiere el interés general."

"Art. 149.1.20 $\ldots$...puertos de interés general... aeropuertos de interés general..."

"Art. 149.1.24a ...obras públicas de interés general..."

"Art. 150.3. El Estado podrá dictar leyes que establezcan los principios necesarios para armonizar las disposiciones normativas de las Comunidades Autónomas, aun en el caso de materias atribuidas a la competencia de éstas, cuando así lo exija el interés general."

"Art. 155.1. Si una Comunidad Autónoma no cumpliere las obligaciones que la Constitución u otras leyes le impongan, o actuare de forma que atente gravemente al interés general de España, el Gobierno, previo requerimiento al Presidente de la Comunidad Autónoma y, en el caso de no ser atendido, con la aprobación por mayoría absoluta del Senado, podrá adoptar las medidas necesarias para obligar a aquélla al cumplimiento forzoso de dichas obligaciones o para la protección del mencionado interés general."

${ }^{2}$ Art. 103.1 de la Constitución: "La Administración Pública sirve con objetividad los intereses generales y actúa de acuerdo con los principios de eficacia, jerarquía, descentralización, desconcentración y coordinación, con sometimiento pleno a la ley y al Derecho." 
materia de manera que I respectiva actuación satisfaga los intereses generales que, sin embargo, quedan sin definir.

3. La insuficiencia del criterio de la mayoría en la definición del concepto de interés general

Una primera aproximación llevaría a pensar que el interés general es aquello que interesa, o desea, una mayoría de ciudadanos; esto es, una suma de los intereses particulares de la mayoría.

Esta concepción fue adoptada en el siglo XVIII por la teoría del utilitarismo, doctrina ética formulada por el británico Jeremy Bentham, quien afirmó que la mejor acción es la que maximiza la utilidad. En este razonamiento asentó su formulación de la doctrina utilitarista, según la cual toda institución, norma o acto humano debe ser juzgado según su utilidad, esto es, la suma de todo placer que resulta de una acción menos el sufrimiento de cualquier persona involucrada en la acción. La aplicación de esta teoría a la política supone que el objetivo de la acción pública es lograr "la mayor felicidad para el mayor número" 3 .

Sin embargo, la mera suma de voluntades de una comunidad no construye el interés general. A un simple nivel intuitivo, podemos percibir que muchos de los servicios públicos -y en especial los servicios sociales- se dirigen a minorías aritméticas de la población. Los parados, los discapacitados, los enfermos o las víctimas de delitos no son una mayoría de la población; sin embargo, los servicios públicos correspondientes a cada uno de estos colectivos sirven de forma innegable al interés general. Cuando se establecen políticas o se desarrollan acciones concretas de apoyo a las minorías no se están satisfaciendo de forma directa o inmediata los intereses de la mayoría, sino los de esas minorías. Sin embargo, es indudable que la protección de dichas minorías tiene un alcance general, aunque sea sólo por el hecho de que son colectivos indeterminados: cualquier ciudadano puede caer enfermo y necesitar los servicios de salud pública, cualquier ciudadano puede ser víctima de un delito y precisar el auxilio del servicio de seguridad pública, cualquier trabajador por cuenta ajena puede ser despedido y precisar las coberturas por desempleo, etc.

Por otra parte, la idea de suma de intereses particulares conduce a un resultado insatisfactorio. ¿Cómo se suman los intereses particulares? Es precisamente la dificultad de satisfacer a todos los ciudadanos por igual lo que obliga a construir un concepto de interés general. La diversidad de los individuos, valor que protege nuestro ordenamiento constitucional, conduce indefectiblemente a una divergencia entre sus gustos, sus ideas y sus necesidades. El interés general no es, por tanto, la acumulación desordenada de los intereses de todos y cada uno de los miembros de la comunidad. Aunque contásemos con un instrumento para la fiable medición de los intereses y voluntades de cada uno de los ciudadanos, sería un instrumento inservible porque el interés general no se construye mediante la acumulación sin más de los intereses particulares.

El interés general no es por tanto el interés de la mayoría. La protección de los mayores, de los discapacitados o de los excluidos no ofrece una utilidad inmediata a la sociedad en su conjunto, sino a dichos colectivos en concreto. Sin embargo, no cabe duda que las correspondientes políticas públicas responden a la satisfacción del interés general, aunque se refieran a minorías.

\footnotetext{
${ }^{3}$ Los fundamentos de la doctrina utilitarista se exponen de modo principal en la obra Introducción a los Principios de Moral y Legislación de Jeremy Bentham, escrita en 1789.
} 
La doctrina del utilitarismo, así formulada, no acaba de explicar el desarrollo de las políticas sociales del Estado de Bienestar durante el siglo XX, al menos de aquellas políticas dirigidas a los colectivos minoritarios. Desde el punto de vista del liberalismo es insostenible la idea de que un individuo saque beneficio de lo que contribuyen el resto de individuos. Sin embargo, desde la óptica de los derechos, y en especial de los derechos humanos, la acción del Estado en favor de las minorías beneficia, aunque sea de un modo abstracto, a la ciudadanía en su conjunto. Afirmar que el interés general coincide con el interés de la mayoría llevaría a ignorar las necesidades de las minorías, idea incompatible con el principio de igualdad y con el fundamento mismo de la democracia.

Sin embargo, es de justicia señalar que Bentham no concebía la utilidad material como un fin en sí mismo, sino como un medio de procurar el bienestar social. Téngase en cuenta que este pensador era, ante todo, un reformador social. Cabe preguntarse en este punto si hay una relación entre interés general y utilidad.

La utilidad material es, o puede ser, un instrumento para la satisfacción del interés general. Sin embargo, hay muchas finalidades de interés general que no se alcanzan con utilidades materiales.

Un criterio puramente utilitarista no basta para explicar la construcción del concepto de interés general. Los intereses colectivos no se quedan en el ámbito económico o material, sino que lo exceden. El interés general no se puede confinar en el campo de la Economía, pues corresponde más bien al del Derecho. Algunas finalidades de interés general se satisfacen mediante utilidades materiales, pero otras no. En muchas dimensiones, el interés general no tiene que ver con la utilidad material. Las necesidades del ser humano en asuntos como la cultura, la educación, la realización espiritual $y$, en definitiva, todas las que tienen que ver con el libre desarrollo de la personalidad (artículo 10.1 de la Constitución), requieren algo más que una utilidad material para su satisfacción. Es más, la satisfacción de los intereses materiales requiere en muchas ocasiones la adopción de criterios de gasto, de manera que la rentabilidad económica no es un criterio que deba ser tenido en cuenta en la prestación de los servicios públicos. Los servicios públicos no son económicamente rentables, aunque sí han de ser socialmente rentables. En los servicios públicos, que por definición son de interés general, el criterio de rentabilidad económica debe ser sustituido por el de rentabilidad social.

\section{El interés general como concepto jurídico indeterminado}

El carácter abstracto e indeterminado de la cláusula "interés general" parece razón suficiente para incluirla en la categoría de concepto jurídico indeterminado. López Calera (2010: 133) ha afirmado que hay una unanimidad doctrinal en considerar que el concepto de interés público es un concepto jurídico indeterminado.

El concepto jurídico indeterminado supone un enunciado que de algún modo es impreciso en sus límites, por resultar vagos o generales, pero que puede concretarse en la aplicación que realiza el operador jurídico a un caso concreto. De este modo, hay conceptos que no admiten una delimitación rigurosa, pero que pueden predicarse de las circunstancias y elementos del hecho concreto al que se aplican.

La principal virtud del concepto jurídico indeterminado es que permite distinguir si en determinadas actuaciones de la Administración se ha respetado el principio de legalidad o si, por el contrario, se ha incurrido en una arbitrariedad, figura expresamente prohibida por nuestra Constitución. Si la discrecionalidad administrativa permite a la Administración la elección entre alternativas todas ellas 
válidas, entre indiferentes jurídicos, el concepto jurídico indeterminado, precisado en el momento de la aplicación, conduce a una única solución válida en el caso concreto. La ley utiliza juicios de experiencia o de valor que, en su aplicación, llevan a una "unidad de solución justa" en cada caso.

El profesor García de Enterría mencionaba en su Curso de Derecho Administrativo ejemplos de conceptos jurídicos indeterminados que están presentes en las distintas ramas del Derecho público y del privado. Entre otros, recoge los de "interés social", "necesidad pública", "utilidad pública" e "interés público", esto es, conceptos muy cercanos al de interés general que se contiene en nuestro texto constitucional.

Podemos convenir en que el interés general es un concepto jurídico indeterminado, pero también es algo más. Si la figura del concepto indeterminado permite una adecuada aplicación de la norma jurídica al caso concreto -y en este sentido opera como criterio interpretativo- el interés general excede esta visión, pues también alcanza en nuestro texto constitucional la dimensión de un auténtico principio general del Derecho. En primer lugar, porque las normas de Derecho Administrativo han de interpretarse en el sentido más favorable a los intereses generales. También porque el interés general es el bien jurídico que debe perseguir toda actividad administrativa. En este sentido, el interés general excede la simple consideración de concepto jurídico indeterminado. Las normas administrativas y las actuaciones administrativas son legítimas en la medida en que protegen un bien jurídico, y ese bien jurídico contiene siempre y en todo caso elementos y caracteres de servicio al interés general.

El servicio al interés general es por tanto un principio básico de actuación de las Administraciones Públicas, principio que orienta su labor y da sentido a su propia existencia.

Para Álvarez García (1996: 170), la actuación de los poderes públicos tiene un carácter teleológico. El Derecho es un sistema de normas y principios destinados a organizar y regular la realidad social, pero "estas normas y principios jurídicos carecerían de toda justificación si fuesen considerados exclusivamente en sí mismos, encontrando, por el contrario, todo su sentido en función del fin específico para el que han sido establecidos". En efecto, la organización y el ejercicio del poder público se justifican por sus funciones de gestión de los recursos públicos para la consecución de unos fines que son comunes a los distintos individuos y grupos que conforman el entramado social.

Esta concepción teológica de la actuación administrativa encuentra su soporte en el art. 103.1 de la Constitución Española, que afirma que "la Administración Pública sirve con objetividad los intereses generales", pero también en el 106.1, que establece el control por los tribunales de la legalidad de la actuación administrativa, "así como el sometimiento de ésta a los fines que la justifican".

En definitiva, cabe afirmar que el interés general es un concepto jurídico indeterminado que requiere concreción en la aplicación de la norma jurídica al supuesto de hecho y excluye por tanto la arbitrariedad en la actuación administrativa. Pero no sólo es un concepto jurídico indeterminado, sino que opera también como principio de actuación de las Administraciones Públicas y como principio general del Derecho o criterio para la interpretación de las normas jurídicas. 


\section{El contenido del concepto de interés general}

El bien común se refiere al beneficio de las personas en cuanto seres integrados en una comunidad, al bien humano considerado desde la integración de la persona en la estructura social, a la articulación del Derecho para el disfrute conciliado de los derechos individuales y el común disfrute de lo público.

En una democracia, el poder público debe procurar la conciliación del interés particular con el general, según se deduce de la lectura del artículo 10.1 de nuestra Constitución:

"Art. 10.1. La dignidad de la persona, los derechos inviolables que le son inherentes, el libre desarrollo de la personalidad, el respeto a la ley y a los derechos de los demás son fundamento del orden político y de la paz social"

Este artículo se refiere al fundamento de la legitimidad del poder. El poder es legítimo en la medida en que respeta la dignidad de la persona, protege los derechos inviolables que le son inherentes, promueve las condiciones para el libre desarrollo de la personalidad y garantiza el imperio de la ley en el marco de la igualdad. Dicho de otra manera, el poder adquiere legitimidad en el servicio a los valores relacionados con la justicia. La vida en sociedad implica la existencia de una serie de bienes y valores que son de todos y de ninguno, bienes y valores que exceden el ámbito individual y que sin embargo benefician a la persona. El interés general se refiere a la protección de estos bienes y valores que exceden al individuo; en definitiva, a la idea de justicia.

En consecuencia, lo que es justo se convierte en necesario. El profesor Álvarez García (1996: 161-165) incorpora al debate doctrinal sobre el interés general la noción de necesidad como móvil o motivación de la actuación de los poderes públicos, aunque advierte la inutilidad de todo intento de ofrecer un concepto abstracto de necesidad. De hecho, el de necesidad es un concepto jurídico indeterminado, por las mismas razones por las que el concepto de interés general también lo es. En cualquier caso, según este autor, "la necesidad opera como instrumento jurídico de conexión entre el elemento circunstancial o fáctico y el elemento teleológico".

En este sentido, un análisis de la legitimidad de una norma o actuación administrativa concreta exige comprobar si realmente es necesaria para alcanzar fines de interés general. De esta forma, el concepto de necesidad aporta luz a la cuestión de la definición y satisfacción de los intereses generales.

Otro de los aspectos a tener en cuenta es el de la aparente contradicción entre el interés particular y el general. Observa López Calera (2010: 128-129) que entre los ciudadanos surgen conflictos que en principio atañen sólo a sus intereses particulares, pero como compete a los poderes públicos el mantenimiento de la paz social, el Derecho debe ofrecer una solución a ese conflicto entre particulares porque tiene una dimensión que afecta a la colectividad. De este modo, interés particular e interés general no son conceptos contradictorios o enfrentados, sino elementos que deben ser conciliados por las normas jurídicas y por la acción de los poderes públicos.

Podría parecer que el interés general se contrapone a los intereses privados o particulares, pero también desde estos se sirve al interés general. Adam Smith escribió en 1776: "no es de la benevolencia del carnicero, cervecero o panadero de donde obtendremos nuestra cena, sino de su preocupación por sus propios intereses" (1994: 46). El interés particular no es incompatible con el general, sino normalmente 
complementario. La iniciativa privada y las motivaciones puramente particulares pueden contribuir a los intereses colectivos. Sin embargo, en el caso del funcionamiento de los servicios públicos es más plausible la contradicción con el interés particular, sobre todo cuando lo que se aplican al ciudadano son actos de gravamen.

El concepto de interés general, entendido como bien común o voluntad general, es consustancial al nacimiento del Estado, pues ha operado desde siempre como justificación misma del poder. Sin embargo, el interés general en una Constitución democrática no es ya una simple cláusula de justificación del poder, sino el elemento legitimador de las normas jurídicas y de la acción política. El interés general, una vez juridificado en la Constitución, se convierte en clave de legitimación de la adopción de las decisiones y de las políticas públicas.

Sin embargo, precisar su contenido no es tarea fácil, pues exige una valoración de elementos no exclusivamente técnicos, sino también políticos y jurídicos. Alejandro Nieto (1991: 2188; 1994: 36) ha puesto de relieve en repetidas ocasiones la debilidad comparativa de la protección de los intereses generales, desde una visión un tanto escéptica de las capacidades de los poderes públicos en esta tarea.

En un intento de delimitar el concepto, el profesor Luciano Parejo (1998: 606607 ) ha afirmado que el interés general es una cláusula abstracta y formal cuya función consiste en representar cualquier bien jurídico protegido por la comunidad jurídica e identificado y determinado como tal por el poder público para la resolución de los problemas sociales y la satisfacción de las necesidades colectivas. Esta categoría genérica no tiene un contenido material propio preciso, pero su grado de imprecisión es variable: mientras que el Legislador tiene una amplia libertad para operar con el concepto, pues su único límite es la Constitución, la Administración pública se mueve en unos límites mucho más estrechos sobre la concreción legislativa sucesiva del interés general.

En este punto se plantea una cuestión fundamental: si el interés general debe ser apreciado desde la perspectiva jurídica o desde la ideológica. La primera consiste en precisar el significado y alcance político de los intereses generales en relación con el Estado y la sociedad, siendo esta la línea de pensamiento más antigua y más trabajada. La segunda perspectiva es la jurídica, que conduce a problemas más profundos, porque requiere una concreción en cada acto de manejo de conceptos por parte del operador jurídico (Nieto 1991: 2190-2191). Destaca en este punto el trabajo de Peter Häberle (1970), calificado como "monumental" por Nieto. El esfuerzo de Häberle se encamina a despojar el concepto de sus connotaciones ideológicas para estudiarlo desde la perspectiva jurídica, como problema jurídico y no ideológico, pues considera que sólo el análisis legislativo y jurisprudencial pueden dotar al concepto de los contornos necesarios para perfilarlo como herramienta jurídica.

Observa el profesor Nieto (1991: 2211) que el interés general como concepto político opera como clave de justificación del poder: "la ideología del interés general ha servido siempre para legitimar el poder y al mismo tiempo (en una contradicción, aparentemente paradójica, pero en realidad inevitable) para limitarlo".

En mi opinión, las dimensiones jurídica y política del interés general no tienen por qué ser excluyentes. El interés general es un concepto político pero también jurídico. Es político en la medida en que su satisfacción depende de las decisiones de los poderes públicos, influidos por ideologías que orientan en uno u otro sentido las agendas de los gobiernos y el consiguiente destino de los recursos públicos. Es un 
concepto político porque el parlamentarismo democrático define un margen de actuación más o menos amplio en el que caben las distintas opciones políticas. No se puede ignorar el hecho de que toda acción o política encaminada a la satisfacción del interés general partirá del posicionamiento ideológico del actor de dicha acción o del gestor de dicha política. Pero es sobre todo un concepto jurídico precisamente por esto, porque el marco constitucional sirve como espacio de actuación pero también como límite a la actuación de los poderes públicos.

La satisfacción del interés general es por tanto un criterio fundamental de las políticas públicas, pero también un límite a las decisiones de los gestores de lo público. Las medidas o actuaciones que resulten ser contrarias o lesivas al interés general serán sin duda contrarias al ordenamiento jurídico.

\section{Conclusiones}

La Política y el Derecho son motores de la transformación social. Ni Política ni Derecho pueden concebirse sin una finalidad. Aristóteles definió al hombre como zoon politikon, como animal social que desarrolla su vida en el seno de una comunidad con el fin de alcanzar la felicidad, y concibe el Estado como una comunidad de iguales que aspiran a la mejor vida posible. La figura de los intereses generales remite precisamente a esta idea, pues se refieren a la consecución de la mejor vida posible para la ciudadanía.

El interés general es un concepto político, porque se refiere a la vida en sociedad bajo la necesaria presencia del Estado, que es la organización política de una comunidad en un territorio para la satisfacción de los intereses comunes.

El interés general es también un concepto jurídico, porque se materializa mediante la creación de normas jurídicas y su aplicación por los operadores jurídicos, bajo la supervisión de los tribunales de justicia.

El interés general es también un criterio orientador de las políticas públicas y de las concretas actuaciones administrativas, pues así lo impone el art. 103.1 de la Constitución Española cuando declara que "la Administración Pública sirve con objetividad los intereses generales".

También es un principio general del Derecho, en la medida en que tiene carácter informador del ordenamiento jurídico, permite interpretar las normas jurídicas y cubre las lagunas legales.

Y por último, pero no menos importante, el servicio a los intereses generales es un valor democrático. No puede ignorarse que todo el Derecho Público se sustenta en un sistema de valores. Sin esos valores, la actuación del Estado pierde su legitimidad y el ordenamiento jurídico se convertiría en un cáscara hueca carentes de contenido.

\section{Bibliografía}

ÁlVAREZ GARCíA, V. (1996), El concepto de necesidad en Derecho Público, Civitas, Madrid.

BENTHAM, J. (1789), Introducción a los Principios de Moral y Legislación, traducción de Francisco Ferrer y Valls, Imprenta de Tomás Jordán, Madrid. 
CALVO GARCÍA, M. (2004), Teoría del Derecho (2a ed.), Tecnos, Madrid.

HÄBERLE, P. (1970), Öffentliches Interesse als juristisches Problem. Eine Analyse von Gesetzgebung und Rechtsprechung, Athanäum Verlag, Basel-HamburG.

LÓPEZ CALERA, N. (2010), "El interés público: entre la ideología y el Derecho", Anales de la Cátedra Francisco Suárez, 44, pp. 123-148.

MUÑOZ MACHADO, S. (2011), Tratado de Derecho Administrativo y Derecho Público General, tomo IV, lustel, Madrid.

NIETO GARCÍA, A. (1991), "La Administración sirve con objetividad los intereses generales". En: Martín-Retortillo, S. (coord.), Estudios sobre la Constitución Española, libro homenaje al profesor Eduardo García de Enterría, tomo III, Madrid, Civitas, pp. 2185-2253.

NIETO GARCÍA, A. (1994), Derecho Administrativo Sancionador (2 ${ }^{\mathrm{a}}$ ed.), Tecnos, Madrid.

PAREJO ALFONSO, L. (19998), "Capítulo X: El interés general o público. Las potestades generales o formales para su realización". En: PAREJO ALFONSO, L., JIMÉNEZ-BLANCO, A. y ORTEGA ALVAREZ, L., Manual de Derecho Administrativo (5 $5^{\mathrm{a}}$ ed.), Volumen I, Barcelona, Ariel Derecho, pp. 605-703.

SMITH, A. (1994 [1776]), La riqueza de las naciones, Alianza Editorial, Madrid. 